\title{
Influence of a Probiotic on Productivity, Meat Components, Lipid Metabolism, Caecal Flora and Metabolites, and Raising Environment in Broiler Production
}

\author{
Tsuyoshi ENDO ${ }^{1,2}$ and Masuo NAKANO \\ ${ }^{1}$ The United Graduate School of Agricultural Science, Iwate University, Morioka-shi 020-8550, Japan \\ ${ }^{2}$ Total Science Institute Zukohsha Co., Ltd., Obihiro-shi 080-0048, Japan \\ ${ }^{3}$ Department of Bioresource Obihiro University of Agriculture and Veterinary Medicine, \\ Obihiro-shi 080-8555, Japan
}

(Received November 16, 1998 ; Accepted March 9, 1999)

\begin{abstract}
The effect of a probiotic comprised of Bacillus, Lactobacillus. Streptococcus, Clostridium. Saccharomyces and Candida species on productivity, meat components, lipid metabolism, caecal flora and metabolites, and the raising environment of broilers were studied. The probiotic increased productivity in males. Lipid in meats increased, while water in thigh meat decreased in male broilers administered the probiotic. The probiotic decreased water and increased lipid content in the liver ( $\mathrm{P}$ $<0.05)$. In the probiotic group, the cholesterol concentration of thigh meat and liver decreased $(\mathrm{P}<$ $0.05)$. The linolenic acid and the unsaturated fatty acid/saturated fatty acid ratio in pectoral meat was increased $(P<0.05)$ by administration of the probiotic. A similar effect was also noticed in thigh meat. The probiotic decreased the number of Enterobacteriaceae, i.e., E.coli and Salmonella in caeca. The probiotic decreased the $\mathrm{pH}$ value of caecal contents and ammonia $(\mathbf{P}<0.05)$, and increased the acetic acid concentration $(\mathrm{P}<0.05)$. Ammonia, and sulfate compounds in the raising space decreased in the probiotic group. The number of Enterobacteriaceae in the drift on the raising environment was decreased by administration of the probiotic, and those of Lactobacillus and Streptococcus increased. These results suggested that the probiotic improved intestinalflora and the raising environment and, as a result, reduced the stress and enhanced the productivity and meat quality of broilers.
\end{abstract}

Animal Science Journal 70 (4) : 207-218, 1999

Key words : Probiotic, Lipid metabolism, Caecal flora, Raising environment, Broiler production

Antibiotics are in widespread use for inhibiting disease and promoting growth, but there are common problems such as the appearance of drug-resistant bacteria, drug residuals in meat, milk and eggs, and the destruction of normal microflora ${ }^{23)}$. This makes it necessary to develop alternatives to using antibiotics. Probiotics are reported to be effective as one of these alternatives ${ }^{9,36)}$. A probiotic, as defined by Fuller $^{8)}$, is a live microbial feed supplement which beneficially affects the host animal by improving its intestinal microbial balance. The administration of probiotics has been reported to improve weight gain and feed conversion ${ }^{8,16,23,25,33,36)}$, exclude pathogenic $\operatorname{organisms}^{2,17,18,26,28)}$, prevent diarrhea ${ }^{18,23)}$, hinder production of harmful matter ${ }^{23,32,36)}$, control blood pressure and the serum cholesterol concentration ${ }^{7,11,24,25,30)}$, and activate immnocytes ${ }^{10,14,15,20)}$. Our laboratory also reported ${ }^{6,7)}$ previously that a mixture of organisms improved the intestinal flora and lowered HMGCoA reductase (NADPH ; EC 1.1.1.34) activity and tended to be hypocholesterolaemic in rats. It was considered that the results obtained for the mixture of bacteria were due to the existence of a symbiotic relationship in the intestine. Intensive production

Corresponding : Masuo NAKANO (fax : +81 (0) 155-49-5559, e-mail : nakano@obihiro.ac.jp)

Anim. Sci. J. 70 (4) : 207-218, 1999 


\section{ENDO and NAKANO}

systems inflict considerable stress on broilers, and decrease productivity and the quality of products. Therefore, employing such a mixture of bacteria is needed for broiler production. The effects of a probiotic comprising Bacillus, Lactobacillus, Streptococcus, Clostridium, Saccharomyces and Candida species given at the level of $3 \mathrm{~g} / \mathrm{kg}$ diet, on productivity, meat components, lipid metabolism, caecal flora and metabolites, and the raising environment of broilers were studied.

\section{Materials and Methods}

\section{Probiotic}

The composition of the probiotic is shown in Table 1. Each microbe was isolated from brown forest soils gathered from western and northern Japan. The final proportion of each microbe was adjusted to $10^{7-8}$ $\mathrm{cfu} / \mathrm{g}$ rice bran using the method described by Fukushima and Nakano ${ }^{6,7)}$.

\section{Animals and diet}

This examination was carried out at farm $S$ (Gunma Prefecture) using two male broiler houses containing about 2,700 broilers, and two female broiler houses containing about 3,300 broilers (Cobb strain). They were divided into two groups. As shown in Table 2, all groups were fed with starter from the day the experiment started to day 21 , grower

Table 1. Microbial composition of the probiotic ${ }^{13}$

Bacillus subtilis

Bacillus natio

Bacillus megaterium

Bacillus thermophilus

Lactobacillus acidophilus

Lactobacillus plantarum

Lactobacillus brevis

Lactobacillus casei

Streptococcus faecalis

Streptococcus lactis

Streptococcus thermophilus

Clostridium butyricum

Saccharomyces cerevisiae

Candida utilis

\footnotetext{
1) Each microbe was regulated at $10^{7-8}$ colony forming
} units/g rice bran. from day 22 to day 35 and finisher from day 36 to shipment day. Throughout the examination the experimental groups were fed feed containing $3 \mathrm{~g}$ probiotic $/ \mathrm{kg}$, and control groups were fed feed containing $3 \mathrm{~g}$ rice bran $/ \mathrm{kg}$. The broilers were allowed free access to the experimental feed and water.

\section{Productivity}

In this study, the productivity of each group was estimated according to a production score calculated by the following method.

Production score=Total final body weight $(\mathrm{kg}) /$ Number of kept broilers/Periods of raising (days)/ Feed conversion $\times 10,000$

Preparation of pectoral and thigh meat, liver, caecal content and accumulating faeces

At the age of 49 days, 6 broilers were randomly selected from each group. The pectoral and thigh meat and the liver were taken right after slaughter. The blood veins and adipose tissues were removed from the meat and liver carefully at $4 \pm 2{ }^{\circ} \mathrm{C}$, then stored at $-30^{\circ} \mathrm{C}$ until analysis. At the same time, the caecal content was taken from the gut. After weighing, part of it was used for the determination of microflora, the remainder was diluted tenfold with desalted water for analysis of the concentration of ammonia, short chain fatty acids and $\mathrm{pH}$ value. Five to 6 accumulated faeces samples were randomly collected from each raising floor and mixed, and portion was used for the determination of microflora.

\section{Meat and liver components}

The pectoral and thigh meat and liver were sliced with a knifc coated with Teflon, and freeze-dried for 72 hours using a freeze-drier (FD-81, Tokyo Rika Kikai Co., Ltd., Tokyo, Japan). Water was calculated from differences of weights before and after freezedrying. The freeze-dried samples were crushed into pieces and mixed uniformly. Protein was determined by Kjeldahl methods. Lipid was extracted from the meat and liver by a mixture of chloroform-methanol $\left(2: 1, \mathrm{v} / \mathrm{v} ;\right.$ Folch et al. $\left.^{3)}\right)$. Ash was calculated from differences of weights before and after heating at $600^{\circ} \mathrm{C}$ for 1 hour with a muffle furnace (FP-42 Yamato Scientific Co., Ltd., Tokyo, Japan). Fatty acid methyl ester derivatives of the total lipid from meat, and of phosphatidylcholine and 
Table 2. Formulation and nutrient concentrations of the diets (\%)

\begin{tabular}{|c|c|c|c|}
\hline \multirow{2}{*}{$\begin{array}{c}\text { Feed } \\
\text { (Age : days) }\end{array}$} & Starter & \multirow{2}{*}{$\frac{\text { Grower }}{(22-35)}$} & Finisher \\
\hline & $(-21)$ & & $\left(36^{-}\right)$ \\
\hline Corn grain & 60.60 & 41.35 & 41.70 \\
\hline Milo & 3.00 & 24.59 & 24.41 \\
\hline Fish meal (65\% CP) & 7.00 & & \\
\hline Meat \& Bone meal ( $45 \% \mathrm{CP})$ & 3.00 & 0.50 & 0.50 \\
\hline Defatted soybean refuse & 18.75 & 11.63 & 11.60 \\
\hline Defatted non-skin soybean refuse & & 15.00 & 15.00 \\
\hline Gluten & 5.00 & & \\
\hline Alfalfa meal & 0.60 & & \\
\hline Vegetable fat & 0.68 & 3.50 & 3.50 \\
\hline Calcium carbonate & 0.10 & 1.35 & 1.36 \\
\hline Calcium phosphate & 0.79 & 1. 40 & 1.40 \\
\hline Sodium chloride & 0.19 & 0.17 & 0.17 \\
\hline Methionine & 0.04 & 0.17 & 0.17 \\
\hline Lysine & & 0.08 & 0.09 \\
\hline Additive (Vitamin \& Mineral) & 0.25 & 0.25 & 0.10 \\
\hline \multicolumn{4}{|l|}{ Calculation } \\
\hline $\mathrm{CP}(\%)$ & 22.20 & 18.00 & 18.00 \\
\hline $\mathrm{ME}(\mathrm{Kcal} / \mathrm{kg})$ & 3,060 & 3,122 & 3,127 \\
\hline
\end{tabular}

phosphatidylethanolamine from liver were prepared using methanolic $\mathrm{HCl}(50 \mathrm{ml} / \mathrm{l})$ for 3 hours at $125^{\circ} \mathrm{C}$ following the procedure of Nakano and Fischer ${ }^{27)}$, and estimated using a gas-liquid chromatograph (GC9A, Shimadzu, Co., Ltd., Kyoto, Japan) with a glass column $(2.6 \mathrm{~mm} \times 2000 \mathrm{~mm})$ packed with $60-80 \mathrm{mesh}$ chromosolb with diethyleneglycol succinate $(100 \mathrm{~m} l /$ l). Cholesterol contents in meat and liver were acetylated by the method of Matsubara et al. ${ }^{19}$, and measured using a gas-liquid chromatograph (GC-14A, Shimadzu, Co., Ltd., Kyoto, Japan) with a capillary column (HR-52, $0.25 \mathrm{~mm} \times 25 \mathrm{~m}$, Shinwa Chemical Industries, Ltd., Kyoto, Japan). For mineral and phosphorus analyses, about $1.0 \mathrm{~g}$ of dried meat was dissolved in $50 \mathrm{~m} l$ nitric acid at $100^{\circ} \mathrm{C}$ for 1 hour and gradually heated to $250^{\circ} \mathrm{C}$. After concentration to a volume of less than $2 \mathrm{~m} l, 10 \mathrm{~m} l$ nitric acid and $2 \mathrm{~m} l$ perchroric acid were added to the solution and it was heated to $250^{\circ} \mathrm{C}$. After concentration to a volume of less than $2 \mathrm{ml}, 5 \mathrm{ml}$ nitric acid was added and the solution was filtered and expanded to $100 \mathrm{~m} l$ with desalted water. The concentration of minerals in the meat was measured using an atomic absorption spectrophotometer (AA-680, Shimadzu, Co., Ltd., Kyoto, Japan). The phosphorus concentration in meat was determinated by the colorimetric method ${ }^{1)}$.

\section{Caecal flora and caecal metabolites}

The caecal flora was measured by the procedure of Mitsuoka et al. ${ }^{22)}$ with some modifications. After thorough mixing of caecal contents, a series of 10-fold dilutions $\left(10^{-1}\right.$ to $\left.10^{-8}\right)$ was done using anaerobic diluents. From the appropriate dilution, $0.05 \mathrm{~m} l$ aliquots were spread onto three non-selective agar plates : modified Eggerth-Gagnon (EG) agar and glucose blood liver (BL) agar for anaerobes, and trypticase soy blood (TS) agar (BBL, Cockeysville, MD, USA) for aerobes, as well as 9 selective agar media : bifidobacteria selective (BS) agar for bifidobacteria, eubacteria selective (ES) agar for eubacteria, neomycin-brilliant green-taurocholate-blood (NBGT) agar for bacteroidaceae, neomycin-nagler (NN) agar for lecithinase-positive clostridia, modified lactobacilli selective (LBS) agar for lactobacilli, KF streptococcus selective (KF) agar (Merck KGaA, Darmstadt, 


\section{ENDO and NAKANO}

Germany) for streptococci, staphylococcus 110 agar (Difco, Detroit, MI, USA) with phenylethylalcohol and egg yolk suspension (PEES) for staphylococci, desoxycholate hydrogen sulfide lactose (DHL) agar (Merck KGaA, Darmstadt, Germany), and potato dextrose (PD) agar (Merck KGaA, Darmstadt, Germany) with tartaric acid for yeasts. Each EG, BL, BS, ES, NBGT, NN and LBS agar plate was incubated at $37^{\circ} \mathrm{C}$ for 3 days in an anaerobic "steelwool" jar filled with an atmosphere of oxygen-free carbon dioxide. KF, PEES and PD agar plates, and TS and DHL agar plates were incubated aerobically at $37^{\circ} \mathrm{C}$ for 48 hours and 24 hours, respectively. After incubation, each plate was examined for bacterial colonies. The identification of 10 bacterial groups, yeasts and molds was performed by examining colonial and cellular morphologies, the Gram-reaction, spore formation and aerobic growth. The results were expressed as the $\log _{10}$ of the number of bacteria per gram wet weight of caecal content. The $\mathrm{pH}$ value was measured using a $\mathrm{pH}$ meter with a glass-electrode (F-23, Horiba Ltd., Kyoto, Japan). Ammonia concentration was measured by colorimetric determination with a commercial kit (Ammonia Test Wako, Wako Pure Chemical Industries, Ltd., Tokyo, Japan). Preparation of short chain fatty acids (SCFA) in caecal contents was carried out by the procedure of Hara et al. ${ }^{12)}$ and measured using a gas-liquid chromatograph (GC-9A, Shimadzu, Co., Ltd., Kyoto, Japan) with a glass column $(3 \mathrm{~mm} \times 2000 \mathrm{~mm})$ packed with 80-100 mesh chromosorb W-AW DMCS with phosphoric acid $(100 \mathrm{~m} l / l)$ as a liquid phase.

\section{Smell and microflora of raising environment}

Smell was measured by using inspection tubes (Gastec Co., Kanagawa, Japan) held $1 \mathrm{~m}$ above the ground. After thorough mixing of the drift, a series of 10 -fold dilutions $\left(10^{-1}\right.$ to $\left.10^{-7}\right)$ was made in an anaerobic diluent. From the appropriate dilution, $0.05 \mathrm{~m} /$ aliquots were spread onto two non-selective agar plates: modified GAM (GAM) agar (Nissui Pharmaceutical Co., Ltd., Tokyo, Japan) for anaerobes, and TS agar for aerobes, as well as 4 selective agar media : LBS agar for lactobacilli, KF agar for streptococci, DHL agar for Enterobacteriaceae and PD agar with tartaric acid for yeasts. GAM and
LBS agar plates were incubated at $37^{\circ} \mathrm{C}$ for 3 days in an anaerobic "steel-wool" jar filled with an atmosphere of oxygen-free carbon dioxide. KF, TS PD and DHL agar plates were incubated aerobically at $37^{\circ} \mathrm{C}$ for 24 to 48 hours. After incubation, each plate was examined for bacterial colonies. The identifcation of 3 bacterial groups and yeasts was done based on colonial and cellular morphologies, the Gramreaction, spore formation and aerobic growth. The results were expressed as the $\log _{10}$ of the number of bacteria per gram wet weight of the drifts.

\section{Statistical analysis}

Data were analyzed by two way (sex and diet) ANOVA and Duncan's multiple range test (SPSS Ver. 4.0, SPSS Inc., Chicago, IL, USA). Student's $t$ test was used to compare mean differences between $C$. perfringens level in caecum of the control group and that of the probiotic group. Differences were considered significant at $\mathrm{P}<0.05$.

\section{Results and Discussion}

Usual probiotics are comprised of a single or a few microbes. However, as shown in Table 1, the probiotic used in this study consisted of 14 microbes that have individual biological activities ${ }^{15,16,29)}$. It is possible that the effects of the mixture resulted from symbiotic relationships in the intestine rather than the effects of individual species. Using this mixture, the effects of the probiotic on broiler production were studied.

King ${ }^{16)}$, Mohan et al. ${ }^{25)}$, and Yeo and $\mathrm{Kim}^{36)}$ reported that probiotics promoted growth and increased feed efficiency in poultry. In this study, the production score was used for comparison of productivity. Producers aim for a score of 180 or more. As shown in Table 3, the scores of all groups were 190 or more on this farm, so, it was considered that this farm was very productive. Although the rearing periods were only slightly different among the groups, the score in the male group was increased by the probiotic. However, there was no difference between the probiotic group and the control group in females. The reasons for this were unclear in present study. The effect of the probiotic on productivity in the female group tended to be lower than in the male 
Probiotic and Broiler Production

Table 3. Infuence of probiotic administration on body weight, feed conversion and production score in broilers

\begin{tabular}{lcccccc}
\hline \hline & \multicolumn{2}{c}{ Male } & & \multicolumn{2}{c}{ Female } \\
\cline { 2 - 3 } \cline { 5 - 6 } & Probiotic & Control & & Probiotic & Control \\
\hline Period of raising (days) & 56 & 54 & & 62 & 65 \\
Number of kept broilers & 2,676 & 2,640 & & 3,283 & 3,240 \\
Initial body weight (g) & 103 & & 106 & & 124 & 119 \\
Final body weight (kg) & 3.08 & & 2.80 & & 2.85 & 2.95 \\
Total supplied feed (kg) & 16,500 & & 16,500 & & 22,000 & 22,000 \\
Feed conversion & 2.03 & & 2.26 & & 2.38 & 2.33 \\
Production score (PS) & ${ }^{1)}$ & 271 & 229 & & 193 & 195 \\
\hline
\end{tabular}

1) PS $=$ Total final body weight/Number of kept broilers/Period of raising/Feed conversion $\times$ 10,000 .

Table 4. Influence of probiotic administration on water, protein, lipid, ash and mineral concentrations of meat of broilers

\begin{tabular}{|c|c|c|c|c|c|c|c|}
\hline & \multicolumn{2}{|c|}{ Male } & \multicolumn{2}{|c|}{ Female } & \multicolumn{3}{|c|}{$\begin{array}{l}\text { Two-way analysis of } \\
\text { variance ( } P \text { value })\end{array}$} \\
\hline & Probiotic & Control & Probiotic & Control & Diet & Sex & Diet $\times$ Sex \\
\hline \multicolumn{8}{|l|}{ Pectoral meat } \\
\hline Water $(\mathrm{g} / 100 \mathrm{~g}$-wet $)$ & $73.6 \pm 1.1^{1)}$ & $74.1 \pm 0.4$ & $73.6 \pm 0.5$ & $73.2 \pm 0.9$ & $\mathrm{NS}^{2)}$ & NS & NS \\
\hline Protein $(g / 100$ g-wet $)$ & $23.4 \pm 0.8$ & $23.2 \pm 0.4$ & $23.5 \pm 0.5$ & $23.8 \pm 0.8$ & NS & NS & NS \\
\hline Lipid $(g / 100$ g-wet $)$ & $1.1+0.2$ & $0.8+0.1$ & $0.9+0.2$ & $0.8+0.2$ & NS & NS & NS \\
\hline Ash (g/100g-wet) & $1.9 \pm 0.3$ & $2.0 \pm 0.2$ & $2.0 \pm 0.2$ & $2.1 \pm 0.2$ & NS & NS & NS \\
\hline Calcium (mg/100 g-wet) & $7.8 \pm 0.7$ & $9.9 \pm 1.4$ & $7.4 \pm 0.7$ & $11.2 \pm 1.5$ & 0.000 & NS & NS \\
\hline Magnesium (mg/100 g-wet) & $27.5 \pm 1.0$ & $29.0 \pm 1.2$ & $28.6 \pm 1.0$ & $29.6 \pm 2.4$ & NS & NS & NS \\
\hline Potassium (mg/100 g-wet) & $361.8 \pm 20.4$ & $356.1 \pm 9.3$ & $364.9 \pm 10.3$ & $365.1 \pm 16.6$ & NS & NS & NS \\
\hline Iron $(\mathrm{mg} / 100 \mathrm{~g}$-wet $)$ & $0.4 \pm 0.0$ & $0.5 \pm 0.1$ & $0.5 \pm 0.1$ & $0.4 \pm 0.0$ & NS & NS & NS \\
\hline Sodium (mg/100 g-wet) & $63.1 \pm 4.3$ & $65.3 \pm 7.2$ & $69.1 \pm 5.0$ & $73.8 \pm 10.7$ & NS & 0.023 & NS \\
\hline Phosphorus (mg/100 g-wet) & $209.1 \pm 17.0$ & $223.0 \pm 6.4$ & $224.5 \pm 4.9$ & $221.8 \pm 14.8$ & NS & NS & NS \\
\hline \multicolumn{8}{|l|}{ Thigh meat } \\
\hline Water (g/100 g-wet) & $74.8 \pm 0.7^{b}$ & $76.3 \pm 0.4^{\mathrm{a}}$ & $76.0 \pm 0.6^{a}$ & $76.2 \pm 0.6^{a}$ & 0.004 & 0.042 & 0.011 \\
\hline Protein (g/100g-wet) & $19.1 \pm 0.2$ & $19.3 \pm 0.4$ & $19.3 \pm 0.5$ & $19.4 \pm 0.4$ & NS & NS & NS \\
\hline Lipid (g/100 g-wet) & $4.1 \pm 0.5^{\mathrm{a}}$ & $2.8 \pm 0.6^{b}$ & $2.9 \pm 0.7^{b}$ & $2.8 \pm 0.6^{b}$ & 0.007 & 0.031 & 0.018 \\
\hline Ash $(g / 100 g$-wet $)$ & $1.9 \pm 0.3$ & $1.7 \pm 0.2$ & $1.8 \pm 0.3$ & $1.6 \pm 0.1$ & NS & NS & NS \\
\hline Calcium (mg/100g-wet) & $7.2 \pm 0.5$ & $6.2 \pm 0.4$ & $6.8 \pm 0.7$ & $6.4 \pm 0.7$ & 0.005 & NS & NS \\
\hline Magnesium (mg/100 g-wet) & $22.8 \pm 1.1^{\mathrm{a}}$ & $20.8 \pm 0.9^{\circ}$ & $23.1 \pm 0.9^{a}$ & $23.3 \pm 0.5^{\mathrm{a}}$ & 0.014 & 0.001 & 0.005 \\
\hline Potassium (mg/100g-wet) & $319.4 \pm 19.1^{b}$ & $299.8 \pm 12.1^{\mathrm{c}}$ & $311.6 \pm 8.4^{b c}$ & $341.7 \pm 8.8^{\mathrm{a}}$ & NS & 0.004 & 0.000 \\
\hline Iron (mg/100 g-wet) & $0.8 \pm 0.1$ & $1.0 \pm 0.1$ & $0.8 \pm 0.1$ & $0.9 \pm 0.0$ & 0.002 & 0.023 & NS \\
\hline Sodium (mg/100 g-wet) & $85.9 \pm 5.2$ & $92.5 \pm 2.2$ & $82.4 \pm 4.8$ & $86.4 \pm 2.5$ & 0.004 & 0.008 & NS \\
\hline Phosphorus (mg/100 g-wet) & 188. $2 \pm 11.9^{\mathbf{a b}}$ & $179.1 \pm 6.8^{b}$ & $187.7 \pm 5.9^{\mathrm{ab}}$ & $197.6 \pm 6.0^{a}$ & NS & 0.013 & 0.009 \\
\hline
\end{tabular}

${ }^{1)}$ Values provided are the mean $\pm S D$ for 6 animals, and those in each row with different supercripts ${ }^{a-c}$ are significantly different $(\mathbf{P}<0.05)$.

${ }^{2)}$ NS : not significant.

Anim. Sci. J. 70 (4) : 207-218, 1999 


\section{ENDO and NAKANO}

Table 5. Influence of probiotic administration on fatty acid composition and properties of lipids in meat of broilers (mole \%)

\begin{tabular}{|c|c|c|c|c|c|c|c|}
\hline & \multicolumn{2}{|c|}{ Male } & \multicolumn{2}{|c|}{ Female } & \multirow{2}{*}{$\frac{\text { Two-way analysis }}{\text { Diet }}$} & \multirow{2}{*}{\multicolumn{2}{|c|}{$\frac{\text { of variance }(P \text { value })}{\text { Sex } \quad \text { Diet } \times \text { Sex }}$}} \\
\hline & Probiotic & Control & Probiotic & Control & & & \\
\hline \multicolumn{8}{|c|}{ Pectoral meat } \\
\hline $16: 0$ & $24.1 \pm 1.0^{1)}$ & $24.8 \pm 1.8$ & $24.6 \pm 0.9$ & $25.7 \pm 1.3$ & $\mathrm{NS}^{2)}$ & NS & NS \\
\hline $16: 1$ & $4.3 \pm 1.0$ & $3.4 \pm 1.2$ & $3.4 \pm 0.7$ & $3.6 \pm 0.5$ & NS & NS & NS \\
\hline $18: 0$ & $9.1 \pm 0.8$ & $10.3 \pm 1.3$ & $10.3 \pm 1.1$ & $10.0=1.0$ & NS & NS & NS \\
\hline $18: 1$ & $35.8+1.2$ & $33.8 \pm 3.3$ & $34.1 \pm 2.0$ & $33.3 \pm 3.0$ & NS & NS & NS \\
\hline $18: 2$ & $19.4 \pm 1.4$ & $19.2 \pm 1.9$ & $19.1 \pm 1.7$ & $19.4 \pm 1.2$ & NS & NS & NS \\
\hline $18: 3$ & $1.6 \pm 0.3$ & $1.1 \pm 0.2$ & $1.5 \pm 0.2$ & $1.2 \pm 0.4$ & 0.002 & NS & NS \\
\hline $20: 4$ & $3.6 \pm 0.9$ & $4.7 \pm 1.6$ & $4.6 \pm 0.8$ & $4.0 \pm 1.1$ & NS & NS & NS \\
\hline $22: 6$ & $2.1 \pm 0.8$ & $2.7 \pm 0.8$ & $2.4 \pm 0.4$ & $2.8 \pm 0.4$ & NS & NS & NS \\
\hline $\mathrm{U} / \mathrm{S}^{3)}$ & $2.01 \pm 0.12$ & $1.85 \pm 0.13$ & $1.87 \pm 0.06$ & $1.81 \pm 0.17$ & 0.039 & NS & NS \\
\hline \multicolumn{8}{|c|}{ Thigh meat } \\
\hline $16: 0$ & $22.6 \pm 1.2$ & $22.9 \pm 1.5$ & $23.1 \pm 1.0$ & $23.7 \pm 1.3$ & NS & NS & NS \\
\hline $16: 1$ & $7.2 \pm 1.1$ & $6.6 \pm 1.2$ & $6.6 \pm 1.1$ & $7.0 \pm 0.6$ & NS & NS & NS \\
\hline $18: 0$ & $6.3 \pm 0.7^{b}$ & $7.7 \pm 0.8^{a}$ & $7.5 \pm 0.7^{\mathrm{a}}$ & $7.4 \pm 0.5^{a}$ & 0.023 & NS & 0.018 \\
\hline $18: 1$ & $37.9 \pm 1.1$ & $36.9 \pm 2.0$ & $36.1 \pm 2.2$ & $35.8 \pm 1.4$ & NS & NS & NS \\
\hline $18: 2$ & $21.5 \pm 1.8$ & $20.1 \pm 2.1$ & $21.0 \pm 2.7$ & $20.7 \pm 1.3$ & NS & NS & NS \\
\hline $18: 3$ & $2.1 \pm 0.3$ & $1.7 \pm 0.2$ & $2.0 \pm 0.3$ & $1.8 \pm 0.2$ & 0.012 & NS & NS \\
\hline $20: 4$ & $1.8 \pm 0.1$ & $2.9 \pm 1.0$ & $2.6 \pm 0.7$ & $2.7 \pm 0.5$ & 0.031 & NS & NS \\
\hline $22: 6$ & $0.7 \pm 0.1^{c}$ & $1.2 \pm 0.3^{\mathrm{ab}}$ & $1.2 \pm 0.3^{4}$ & $0.9 \pm 0.2^{b}$ & NS & NS & 0.000 \\
\hline $\mathrm{U} / \mathrm{S}$ & $2.47 \pm 0.21$ & $2.27 \pm 0.11$ & $2.27 \pm 0.10$ & 2. $22 \pm 1.16$ & NS & NS & NS \\
\hline
\end{tabular}

1) Values provided are the mean $\pm S D$ for 6 animals, and those in each row with different supercripts ${ }^{a-c}$ are significantly different $(\mathrm{P}<0.05)$.

2) NS : not significant.

3) U/S : Unsaturated fatty acid/Saturated fatty acid ratio.

group,probably because female hormones such as progesterone influence gut functions. So it is necessary to increase the quantity of the probiotic as compared with males to improve intestinalflora activity and raise the productivity in females.

Mohan et al. ${ }^{24 j}$ reported that the yolk cholesterol concentration was decreased in layers fed a probiotic containing 5 viable organisms. Mile et al. ${ }^{21)}$ reported that living non-freeze-dried $L$. acidophilus influenced egg quality. However, there are few reports on the effects of probiotic administration on meat quality. Nutrient components of pectoral and thigh meat of broilers administered probiotics are shown in Table 4. The results for meat components in this study were similar to those of Fujimura et al. ${ }^{4)}$ and Tanaka et al.
31) In this study, probiotic administration increased lipid contents, in contrast, it decreased water content in thigh meat of male broilers. These results supported the relationship between probiotic administration and increasing fat digestibility reported by Tortuero $^{33)}$. Protein and ash contents were not affected by probiotic administration. It was considered that some minerals in meat were influenced by the probiotic, but the reasons were unclear in the present study.

Fatty acid is widely believed to be related to taste, odor and flavor characteristics such as mildness, continuity, complexity, fullness, etc. Changes in the fatty acid composition of total lipids from pectoral and thigh meat caused by administration of the 
Probiotic and Broiler Production

Table 6. Influence of probiotic administration on weight, water and lipid concentrations in liver of broilers

\begin{tabular}{|c|c|c|c|c|c|c|c|}
\hline & \multicolumn{2}{|c|}{ Male } & \multicolumn{2}{|c|}{ Female } & \multicolumn{3}{|c|}{$\begin{array}{l}\text { Two-way analysis of } \\
\text { variance ( } P \text { value) }\end{array}$} \\
\hline & Probiotic & Control & Probiotic & Control & Diet & $\operatorname{Sex}$ & $\operatorname{Diet} \times \operatorname{Sex}$ \\
\hline Weight ( $\mathrm{g}$ of $\mathrm{kg}$ body weight) & $19.9 \pm 3.2^{11}$ & $19.0 \pm 4.3$ & $19.0 \pm 3.3$ & $17.9 \pm 4.1$ & $\mathbf{N S}^{2)}$ & NS & NS \\
\hline Water ( $\%$ of wet weight) & $73.0 \pm 1.5$ & $74.0 \pm 1.7$ & $70.5 \pm 2.0$ & $72.9 \pm 1.3$ & 0.022 & 0.016 & NS \\
\hline Lipid ( $\%$ of wet weight) & $3.9 \pm 0.9$ & $3.3 \pm 0.3$ & $5.4 \pm 1.4$ & $3.9 \pm 1.1$ & 0.019 & 0.029 & NS \\
\hline
\end{tabular}

1) Values provided are the mean $\pm S D$ for 6 animals.

${ }^{2)}$ NS : not significant.

Table 7. Influence of probiotic administration on fatty acid composition of liver phospholipids of broilers (mole \%)

\begin{tabular}{|c|c|c|c|c|c|c|c|}
\hline & \multicolumn{2}{|c|}{ Male } & \multicolumn{2}{|c|}{ Female } & \multicolumn{3}{|c|}{ Two-way analysis of variance ( $P$ value) } \\
\hline & Probiotic & Control & Probiotic & Control & Diet & Sex & $\operatorname{Diet} \times \operatorname{Sex}$ \\
\hline \multicolumn{8}{|c|}{ Phosphatidylcholine } \\
\hline $16: 0$ & $24.3 \pm 3.4^{1)}$ & $26.1 \pm 1.7$ & $25.2 \pm 1.8$ & $26.8 \pm 1.0$ & $\mathbf{N S}^{2)}$ & NS & NS \\
\hline $18: 0$ & $27.9 \pm 2.2$ & $25.8 \pm 1.4$ & $29.0 \pm 1.4$ & $22.1 \pm 0.5$ & 0.004 & NS & NS \\
\hline $18: 1$ & $16.8 \pm 6.2$ & $14.7 \pm 4.1$ & $16.0 \pm 2.8$ & $14.2 \pm 3.9$ & NS & NS & NS \\
\hline $18: 2$ & $18.4 \pm 2.9$ & $16.8 \pm 1.9$ & $17.2 \pm 2.3$ & $15.5 \pm 2.0$ & NS & NS & NS \\
\hline $20: 4$ & $10.6 \pm 4.3$ & $13.2 \pm 3.3$ & $10.4 \pm 2.0$ & $12.8 \pm 4.1$ & NS & NS & NS \\
\hline $22: 6$ & $2.0 \pm 1.1$ & $3.4 \pm 1.8$ & $2.2 \pm 0.6$ & $3.7 \pm 1.6$ & 0.017 & NS & NS \\
\hline $20: 4 / 18: 2$ & $0.57 \pm 0.20$ & $0.80 \pm 0.26$ & $0.62+0.18$ & $0.86 \pm 0.38$ & 0.042 & NS & NS \\
\hline $\mathrm{U} / \mathrm{S}^{3)}$ & $0.92 \pm 0.05$ & $0.93 \pm 0.03$ & $0.85 \pm 0.03$ & $0.86 \pm 0.02$ & NS & 0.000 & NS \\
\hline \multicolumn{8}{|c|}{ Phosphatidylethanolamine } \\
\hline $16: 0$ & $16.3 \pm 0.8$ & $18.0 \pm 0.7$ & $17.6 \pm 0.8$ & $19.3 \pm 0.9$ & 0.000 & 0.001 & NS \\
\hline $18: 0$ & $34.0 \pm 1.3$ & $32.3 \pm 0.5$ & $33.4 \pm 1.5$ & $30.5 \pm 1.3$ & 0.000 & 0.026 & NS \\
\hline $18: 1$ & $8.4 \pm 3.2$ & $7.0 \pm 2.2$ & $8.3 \pm 2.1$ & $7.3 \pm 2.7$ & NS & NS & NS \\
\hline $18: 2$ & $13.8 \pm 2.1$ & $10.0 \pm 2.8$ & $12.7 \pm 1.6$ & $10.5 \pm 3.5$ & 0.011 & NS & NS \\
\hline $20: 4$ & $22.1 \pm 2.8$ & $24.4 \pm 1.5$ & $21.8 \pm 2.2$ & $22.9 \pm 2.8$ & NS & NS & NS \\
\hline $22: 6$ & $5.5 \pm 1.8$ & $8.3 \pm 3.0$ & $6.3 \pm 1.3$ & $9.6 \pm 3.4$ & 0.007 & NS & NS \\
\hline $20: 4 / 18: 2$ & $1.67 \pm 0.48$ & $2.67 \pm 1.00$ & $1.76 \pm 0.38$ & $2.46 \pm 1.04$ & 0.015 & NS & NS \\
\hline $\mathrm{U} / \mathrm{S}$ & $0.99 \pm 0.03$ & $0.99 \pm 0.03$ & $0.96 \pm 0.04$ & $1.01 \pm 0.04$ & NS & NS & NS \\
\hline
\end{tabular}

1) Values provided are the mean $\pm S D$ for 6 animals.

2) NS : not significant.

3) U/S : Unsaturated fatty acid/Saturated fatty acid ratio.

probiotic are shown in Table 5. Eight fatty acids, palmitic, palmitoleic, stearic, oleic, linoleic, linolenic, arachidonic and docosahexanonic acids, were detected. Palmitic, oleic, linoleic acids were the major ones. The linolenic acid ratio was significantly higher $(P<0.05)$ in the broilers administered the probiotic. The ratio of palmitoleic acid, which is known as a functional fatty acid with the effect of preventing cerebral apoplexy, was higher in male broilers administered probiotics. Furthermore, the ratio of unsaturated fatty acids to saturated fatty acids (U/S ratio) of total lipids in pectoral meats tended to be higher in broilers that received the probiotic. These results suggested that fat in meat was changed to favorable fat with smooth texture. The reasons for the fatty acid composition affected by probiotic 


\section{ENDO and NAKANO}

Table 8. Influence of probiotic administration on cholesterol concentrations in total lipid of pectoral meat, thigh meat and liver of broilers ( $\mathrm{mg} / \mathrm{g}$ total lipid)

\begin{tabular}{|c|c|c|c|c|c|c|c|}
\hline & \multicolumn{2}{|c|}{ Male } & \multicolumn{2}{|c|}{ Female } & \multicolumn{3}{|c|}{ Two-way analysis of variance ( $P$ value) } \\
\hline & Probiotic & Control & Probiotic & Control & Diet & Sex & Diet $\times \operatorname{Sex}$ \\
\hline Pectoral meat & $44.1 \pm 7.5^{11}$ & $55.0 \pm 11.0$ & $51.0 \pm 8.5$ & $49.6 \pm 7.4$ & $\mathrm{NS}^{2)}$ & NS & NS \\
\hline Thigh meat & $15.5 \pm 2.2$ & $25.9 \pm 5.7$ & $23.0 \pm 5.0$ & $25.7 \pm 4.8$ & 0.003 & NS & NS \\
\hline Liver & $66.0 \pm 15.9$ & $76.2 \pm 10.7$ & 47. $1 \pm 10.9$ & 67. $4 \pm 14.9$ & 0.011 & 0.019 & NS \\
\hline
\end{tabular}

1) Values provided are the mean $\pm \mathrm{SD}$ for 6 animals.

2) NS : not significant.

administration were unclear in the present study, and require further investigation to examine the possible mechanism of function of the probiotic.

Weight, water and lipid contents of livers are shown in Table 6. There was no significantly difference between the broilers with and without the probiotic in the liver weight to body weight. Water content of liver decreased $(P<0.05)$ in broilers administered the probiotic. However, lipid content of liver significantly increased $(\mathbf{P}<0.05)$ in broilers administered the probiotic. It was considered that these results could be explained by the same reasons as for meat.

The fatty acid compositions of phosphatidylcholine and phosphatidylethanolamine of liver are shown in Table 7. Palmitic, stearic, oleic, linoleic, arachidonic and docosahexanonic acids were detected. For liver phosphatidylcholine and phosphatidylethanolamine, the ration of stearic acid tended to be higher, whereas those of palmitic, arachidonic and docosahexanonic acid tended to be lower in the probiotic groups. The U/S ratios of phosphatidylcholine and phosphatidylethanolamine were not affected by the probiotic. When the degrec of $\Delta 6$-desaturation was cstimated as the $20: 4 / 18: 2$ ratio, it was comparable in the control group and probiotic group. Our previous study reported ${ }^{6,7)}$ that this ratio increased significantly in the liver phosphatidylcholine of rats fed a high-fat, high-cholesterol diet with the probiotic but the difference was not significant in rats fed the basal diet. However, in the present study, this ratio tended to be lower in broilers fed the probiotic. The reason for the decrease was unclear, but presumed to be due to the difference of the lipid metabolism. These results require further investigation to examine the possible mechanism of action of the probiotic.

Cholesterol concentrations in total lipids from each tissue are shown in Table 8. The cholesterol concentration of thigh meat was significantly lower $(\mathrm{P}<$ 0.05 ) in broilers that received the probiotic. The cholesterol concentration of liver was also significantly lower $(P<0.05)$ in the probiotic group. It has been reported that probiotics ${ }^{7,11,24,25)}$ and fermented milk $^{30)}$ have hypocholesterolaemic functions. For the cholesterol-lowering mechanism, it has been shown that $L$. acidophilus contributes to the elimination of bile acids and cholesterol in the faeces by its binding action and the inhibition of micelle formation $^{11)}$, and the mixture of organisms and $L$. acidophilus lowered the HMG-CoA reductase activity ${ }^{7}$. It is considered that the probiotic used in this study might regulate cholesterol synthesis in the tissues, and contribute to the elimination of bile acids and cholesterol in the faeces.

It is important to exclude pathogens such as Salmonella and Campylobacter from the gut to improve broiler productivity and food hygiene ${ }^{13,17)}$. Nurmi and Rantala ${ }^{28)}$ reported that caecal contents from Salmonella-free chickens had a protective effect in chickens against Salmonella infection. Francis et al. 9) reported that probiotics decreased coliform counts and increased Lactobacillus counts in the digestive tract of turkey poults. Cole and Fuller ${ }^{2)}$ reported that fermented milk significantly decreased the number of coliform in the gut in rats. Changes in the number of microbes were observed in the caecal microflora (Table 9). The number of Enterobacteriaceae, i.e., E. coli and Salmonella in caeca significantly decreased $(\mathbf{P}<0.05)$ in broilers of the 
Probiotic and Broiler Production

Table 9. Influence of probiotic administration on composition of the caecal microflora of broilers

\begin{tabular}{|c|c|c|c|c|c|c|c|}
\hline & \multicolumn{2}{|c|}{ Male } & \multicolumn{2}{|c|}{ Female } & \multicolumn{3}{|c|}{$\begin{array}{l}\text { Two-way analysis of } \\
\text { variance ( } P \text { value })\end{array}$} \\
\hline & Probiotic & Control & Probiotic & Control & Diet & Sex & $\operatorname{Diet} \times \operatorname{Sex}$ \\
\hline Enterobacteriaceae & $\begin{array}{c}6.12 \pm 0.33^{1)} \\
(100)^{2)}\end{array}$ & $\begin{array}{c}6.85 \pm 0.75 \\
(100)\end{array}$ & $\begin{array}{c}5.57 \pm 0.76 \\
(100)\end{array}$ & $\begin{array}{c}6.30 \pm 0.26 \\
(100)\end{array}$ & 0.006 & 0.030 & $\mathbf{N S}^{4)}$ \\
\hline Streptococcus & $\begin{array}{l}6.33 \pm 0.26 \\
(100)\end{array}$ & $\begin{array}{c}6.21 \pm 0.21 \\
(100)\end{array}$ & $\begin{array}{c}5.79 \pm 0.50 \\
(100)\end{array}$ & $\begin{array}{l}5.97 \pm 0.21 \\
(100)\end{array}$ & NS & 0.008 & NS \\
\hline Staphylococcus & $\begin{array}{c}3.50 \pm 0.61 \\
(100)\end{array}$ & $\begin{array}{c}3.08 \pm 0.79 \\
(100)\end{array}$ & $\begin{array}{c}3.59 \pm 0.37 \\
(100)\end{array}$ & $\begin{array}{c}3.44 \pm 0.74 \\
(100)\end{array}$ & NS & NS & NS \\
\hline Yeasts & $\begin{array}{c}\text { 1. } 76 \pm 0.00 \\
(17)\end{array}$ & $\begin{array}{c}1.99 \pm 0.19 \\
(83)\end{array}$ & $\begin{array}{c}\text { nd. }{ }^{3)} \\
(\quad 0)\end{array}$ & $\begin{array}{c}1.95 \pm 0.24 \\
(67)\end{array}$ & & & \\
\hline Bifidobacterium & $\begin{array}{c}7.96 \pm 0.17^{\mathrm{b}} \\
(100)\end{array}$ & $\begin{array}{c}8.45 \pm 0.20^{\mathrm{a}} \\
(100)\end{array}$ & $\begin{array}{c}7.63 \pm 0.51^{\mathrm{bc}} \\
(100)\end{array}$ & $\begin{array}{c}\text { 7. } 43 \pm 0.40^{\circ} \\
(100)\end{array}$ & NS & 0.000 & 0.024 \\
\hline Eubacterium & $\begin{array}{c}8.29 \pm 0.25^{b} \\
(100)\end{array}$ & $\begin{array}{c}8.78 \pm 0.28^{a} \\
(100)\end{array}$ & $\begin{array}{c}7.20 \pm 0.19^{c} \\
(100)\end{array}$ & $\begin{array}{c}8.20 \pm 0.16^{b} \\
(100)\end{array}$ & 0.000 & 0.000 & 0.008 \\
\hline Lactobacillus & $\begin{array}{c}8.55 \pm 0.30 \\
(100)\end{array}$ & $\begin{array}{c}8.42 \pm 0.09 \\
(100)\end{array}$ & $\begin{array}{c}8.33 \pm 0.37 \\
(100)\end{array}$ & $\begin{array}{c}8.25 \pm 0.11 \\
(100)\end{array}$ & NS & NS & NS \\
\hline Bacteroidaceae & $\begin{array}{c}8.06 \pm 0.46 \\
(100)\end{array}$ & $\begin{array}{c}8.70 \pm 0.38 \\
(100)\end{array}$ & $\begin{array}{c}8.44 \pm 0.56 \\
(100)\end{array}$ & $\begin{array}{c}8.65 \pm 0.69 \\
(100)\end{array}$ & NS & NS & NS \\
\hline C. perfringens & $\begin{array}{c}3.22 \pm 1.04 \\
(100)\end{array}$ & $\begin{array}{c}3.28 \pm 1.10 \\
(100)\end{array}$ & $\begin{array}{l}\text { nd. } \\
(0)\end{array}$ & $\begin{array}{c}3.67 \pm 1.05 \\
(50)\end{array}$ & & & \\
\hline
\end{tabular}

1) Values provided are the mean $\pm S D$ of $\log$ bacterial count per $g$ for 6 animals, and those in each row with different supercripts ${ }^{\mathrm{a}-\mathrm{c}}$ are significantly different $(\mathrm{P}<0.05)$.

${ }^{2)}$ Frequency of occurrence $(\%)$.

${ }^{3)}$ nd. : not detected.

${ }^{4)}$ NS : not significant.

Table 10. Influence of probiotic administration on weight, $\mathrm{pH}$ value, ammonia and short chain fatty acid concentrations in cecum of broilers

\begin{tabular}{|c|c|c|c|c|c|c|c|}
\hline & \multicolumn{2}{|c|}{ Male } & \multicolumn{2}{|c|}{ Female } & \multicolumn{3}{|c|}{$\begin{array}{l}\text { Two-way analysis of } \\
\text { variance ( } P \text { value) }\end{array}$} \\
\hline & Probiotic & Control & Probiotic & Control & Diet & Sex & Diet $\times$ Sex \\
\hline Weight (g-wet) & $10.1 \pm 4.6^{1)}$ & $8.2 \pm 2.0$ & $5.4 \pm 1.8$ & $7.9 \pm 2.9$ & $\mathbf{N S}^{2)}$ & NS & NS \\
\hline $\mathrm{pH}$ value & $7.36 \pm 0.14$ & $7.51 \pm 0.20$ & $7.28 \pm 0.25$ & $7.50 \pm 0.14$ & 0.027 & NS & NS \\
\hline Ammonia ( $\mu \mathrm{g} / \mathrm{g}$-wet) & $506 \pm 146$ & $646 \pm 90$ & $401 \pm 44$ & $430 \pm 69$ & 0.041 & 0.001 & NS \\
\hline Acetic acid ( $\mu$ mole/g-wet) & $64 \pm 13$ & $51 \pm 15$ & $81 \pm 33$ & $52 \pm 17$ & 0.022 & NS & NS \\
\hline Propionic acid ( $\mu$ mole/g-wet) & $16 \pm 6$ & $11 \pm 3$ & $11 \pm 6$ & $14 \pm 5$ & NS & NS & NS \\
\hline Butyric acid ( $\mu$ mole/g-wet) & $14 \pm 6$ & $14 \pm 9$ & $12 \pm 5$ & $14 \pm 6$ & NS & NS & NS \\
\hline
\end{tabular}

1) Values provided are the mean $\pm S D$ for 6 animals.

${ }^{2)}$ NS : not significant.

probiotic group. The number of Eubacterium decreased in broilers fed the probiotic. It was observed that the probiotic had the effect of reducing the number and incidence of $C$. perfringens, which causes necrotic enteritis in chickens ${ }^{5)}$. The reasons for those results were unclear from the present study. 
Table 11. Influence of probiotic administration on ammonia, hydrogen sulfate and methylmercaptane concentration (ppm), and microflora in the drifts on the ground ( $\log _{10} \mathrm{cfu} / \mathrm{g}$ wet weight)

\begin{tabular}{|c|c|c|c|c|}
\hline & \multicolumn{2}{|c|}{ Male } & \multicolumn{2}{|c|}{ Female } \\
\hline & Probiotic & Control & Probiotic & Control \\
\hline \multicolumn{5}{|l|}{ Smell } \\
\hline Ammonia & 4. 2 & 6.7 & 6.2 & 7.8 \\
\hline Hydrogen sulfate & nd. ${ }^{1)}$ & 0.052 & nd. & 0.100 \\
\hline Methylmercaptane & nd. & 0.076 & 0.004 & 0.083 \\
\hline \multicolumn{5}{|l|}{ Microbe } \\
\hline Acrobacteria & 9.33 & 8. 20 & 9.13 & 8.60 \\
\hline Enterobacteriaceae & 6.30 & 6.79 & 7.15 & 7.53 \\
\hline Anaerobacteria & 9.56 & 9.34 & 9.20 & 9.15 \\
\hline Lactobacilli & 9.30 & 9.02 & 9.00 & 8.82 \\
\hline Streptococci & 8.03 & 6.90 & 8.11 & 7.41 \\
\hline Yeasts & nd. & 3.08 & nd. & nd. \\
\hline
\end{tabular}

${ }^{1)}$ nd. : not detected.

However, it may be that microorganisms of the probiotic were activated in the caecum, and introduced short-chain fatty acids and antibiotics, thus controlling pathogenic and harmful bacteria such as $E$. coli.

Weight, pH value, ammonia and the short chain fatty acid concentration in the cacca of broilers are shown in Table 10. The weight of the caecal content was not affected by probiotic administration. $\mathrm{pH}$ value and the ammonia concentration of the caecal content was significantly lower $(\mathrm{P}<0.05)$ in the probiotic group. The acetic acid concentration of the caecal content was significantly higher $(P<0.05)$ in broilers administrated the probiotic. Propionic and butyric acid concentrations were not affected by the probiotic. It was well documented that ammonia generated within the colon in situ is not derived exclusively from urea, but also from bacterial deamination of amino acids, peptides and proteins ${ }^{34)}$. It is also reported that the greater the production and absorption of ammonia, the higher the $\mathrm{pH}$ of the local environment ${ }^{35}$. The decreased caecal ammonia level in this study could have resulted from the suppression of ammonia production in the intestine, or from an acceleration of ammonia absorption from the intestine. It may be that the decreased caecal $\mathrm{pH}$ in this study resulted from the increased levels of microbes, which led to reduction of the production of ammonia, or to enhancement of the production of SCFA such as acetic acid.

Usually, broilers are maintained from starting to shipment in the same space, and the wastes pile up on the floor. Thus, improvement of the intestinal environment affects the raising environment. Odor compound concentrations and levels of microflora in the raising ground are shown in Table 11. Ammonia, hydrogen sulfate and methylmercaptane concentrations tended to be lower in broilers administrated the probiotic. The number of Enterobacteriaceae in the drift on the environment also tended to be lower. Contrariwise, the numbers of aerobacteria, anaerobacteria, Lactobacillus and Streptococcus in the drift on the environment tended to be higher. It may be that the ammonia, hydrogen sulfate and methylmercaptane concentrations in the raising space decreased, with the result that the level of Lactobacillus in the drift from probiotic groups increased and Enterobacteriaceae decreased, as did the caecal microflora.

The probiotic used in this study affected intestinal flora of broilers, improving the raising environment and decreasing the stress. Consequently, the probiotic was able to improve the productivity, product 
Probiotic and Broiler Production

quality, and hygiene in broiler production.

\section{Acknowledgments}

The authors thank Dr. M. Fukushima, Department of Bioresource Obihiro University of Agriculture and Veterinary Medicine for advice and Mr. S. Shimizu and Ms. R. Kado, Total Science Institute Zukohsha Co. Ltd. for experimental assistance.

\section{References}

1) Association of Official Analytical Chemists International (AOAC INTERNATIONAL). Official Methods of Analisis. 16th ed., Maryland. 1995.

2) Coll CB, Fuller R. A note on the effect of host specific fermented milk on the coliform popuration of the neonatal rat gut. Journal of Applied Bacteriology, $56: 495-498.1984$.

3) Folch J, Lees M, Sloane-Stanley GH. A simple method for the isolation and purification of total lipids from animal tissues. Journal of Biological Chemistry, $226:$ 497-509. 1957.

4) Fujimura $S$, Koga $H$, Takeda $H$, Tone N, Kadowaki M, Ishibashi $\mathbf{T}$. Chemical compositions of pectoral meat of Japanese native chicken, hinai-jidori, and broiler of the same and marketing age. Animal Science and Technology, $67:$ 541-548. 1996.

5) Fukata $T$, Hadate $Y$, Baba $E$, Uemura $T$, Arakawa A. Influence of Clostridium perfringens and its toxin in germ-free chickens. Research in Veterinary Science, $44: 68-70.1988$.

6) Fukushima M, Nakano $M$. The effect of a probiotic on faecal and liver lipid classes in rats. British Journal of Nutrition, 73 : 701-710. 1995.

7) Fukushima M, Nakano M. Effects of a mixture of organisms, Lactobacillus acidophilus or Streptococcus faecalis on cholesterol metabolism in rats fed on a fat- and cholesterol-enriched diet. British Journal of Nutrition, $76: 857-867.1996$.

8) Fuller R. Probiotics in man and animals. Journal of Applied Bacteriology, $66: 365-378.1989$.

9) Francis C, Janky DM, Arafa AS, Harms RH. Interrelationship of Lactobacillus and zinc bacitracin in the diets of turkey poults. Poultry Science, 57 : 1687-1689. 1978.

10) Friend BA, Shahani KM. Antitumor properties of lactobacilli and dairy products fermented by lactobacilli. Journal of Food Protection, 47 : 717-723. 1984.

11) Gilliland SE, Nelson CR, Maxwell C. Assimilation of cholesterol by Lactobacillus acidophilus. Applied and Environmental Microbiology, 49 : 377-381. 1985.

12) Hara $H$, Saito $Y$, Nishiyama $H$, Kiriyama $S$. Evaluation of fermentability of acid-treated maize husk by rat caecal bacteria in vivo and in vitro. British Journal of Nutrition, $71: 719-729.1994$.

13) Jones FT, Axtell RC, Rives DV, Sheideler SE, Tarver FR JR, Walker RL, Wineland MJ. A survey of Salmonella contamination in modern broiler production. Journal of Food Protection, 54 : 502-507. 1991.

14) Kato I, Kobayashi S, Yokokura T, Mutai M. Antitumor activity of Lactobacillus casei in mice. GANN, 72:517-523. 1981.

15) Kato I, Yokokura T, Mutai M. Macrophage activation by Lactobacillus casei in mice. Microbiology and Immunology, 27:611-618. 1983.

16) King JOL. Lactobacillus acidophilus as a growth stimulant for pigs. The Veterinarian, $5: 273-280$. 1968.

17) Maruta $K$, Miyazaki $H$, Masuda $S$, Takahashi $M$, Marubashi T, Tadano Y, Takahashi H. Exclusion of intestinal pathogens by continuous feeding with $B a$ cillus subtilis $\mathrm{C}-3102$ and its influence on the intestinal microflora in broilers. Animal Science and Technology, 67: 273-280. 1996.

18) Maruta $\mathrm{K}$, Miyazaki $\mathrm{H}$, Tadano $\mathrm{Y}$, Masuda S, Suzuki A, Takahashi H, Takahashi M. Effects of Bacillis subtilis C-3102 intake on fecal flora of sows and on diarrhea and mortality rate of their piglets. Animal Science and Technology, 67 : 403-409. 1996.

19) Matsubara $Y$, Sawabe A, Iizuka $Y$. Structures of new limoroid glycosides in lemon (Citrus limon BURM. f.) peelings. Agricultural and Biological Chemistry, 54 : 1143-1148. 1990.

20) Matsuzaki T, Yamazaki R, Hashimoto S, Yokokura T. The effect of oral feeding of Lactobacillus casei strain Shirota on immunoglobulin E production in mice. Journal of Dairy Science, 81 : 48-53. 1998.

21) Miles RD, Arafa AS, Harms RH, Carlson CW, Reid BL, Crawford JS. Effects of a living nonfreeze-dried Lactobacillus acidophilus culture on performance, egg quality, and gut microflora in commercial layers. Poultry Science, 60 : 993-1004. 1981.

22) Mitsuoka $T$, Sega $T$, Yamamoto $S$. Eine verbesserte methodik der qualitativen und quantitativen analyse der darmflora von menschen und tieren. Zentralblatt für Bakteriologie Parasitenkunde, Infektionskrankheiten und Hygiene. 1. Abt. Medizinisch-hygienische Bacteriologie, Virusforschung und Parasitologie. 
Originale, $195: 455-469.1965$.

23) Mitsuoka T. Using probiotics in animal production. Bifidus, 5 : 1-18. 1991.

24) Mohan B, Kadirvel, Bhaskaran M, Natarajan A. Effect of probiotic supplementation on serum/yolk cholesterol and on egg shell thickness in layers. British Poultry Science, 36 : 799-803. 1995.

25) Mohan B, Kadirvel, Natarajan A, Bhaskaran M. Effect of probiotic supplementation on growth, nitrogen utilization and serum cholesterol in broilers. British Poultry Science, 37 : 395-401. 1996.

26) Muralidhara KS, Sheggeby GG, Elliker PR, England DC, Sandine WE. Effect of feeding lactobacilli on the coliform and Lactobacillus flora of intestinal tissue and feces from piglets. Journal of Food Protection. 40 : 288-295. 1977.

27) Nakano M, Fischer W. The glycolipids of Lactobacillus casei DSM20021. Hoppe-Seyler's Zeitschrift für Physiologische Chemie, 358 : 1439-1453. 1977.

28) Nurmi E, Rantala M. New aspects of Salmonella infection in broiler production. Nature, $241: 210^{-}$ 211. 1973.

29) Ozawa K, Yokota H. Effects of administration of Bacillus subtilis strain BN on intestinal flora of weanling piglets. Japanese Journal of Veterinary Science, 43 : 771-775. 1981.

30) Suzuki Y, Kaizu H, Yamauchi Y. Effects of cultured milk on serum cholesterol concentrations in rats which fed high-cholesterol diets. Animal Science and Technology, 62 : 565-571. 1991.

31) Tanaka K, Youn B S, Suntoso U, Ohtani S, Sakaida M. Effects of fermented products from chub mackerel extracts on growth and carcass composition, hepatic lipogenesis and on contents of various lipid fractions in the liver and the thigh muscle of broilers. Animal Science and Technology, 63 : 32-37. 1992.

32) Terada A, Hara H, Li TS, Yagi S, Ichikawa H, Nishi J, Ko SH, Mitsuoka T. Effect of a microbial preparation on fecal flora and fecal metabolic products of pigs. Animal Science and Technology, 65 : 806-814. 1994.

33) Tortuero F. Influence of the implantation of Lactobacillus acidophilus in chicks on the growth, feed conversion, malabsorption of fats syndrome and intestinal flora. Poultry Science, 52 : 197-203. 1973.

34) Vince A, Down PF, Murison J, Twigg FJ, Wrong OM. Generation of ammonia from non-urea sources in a fecal incubation system. Clinical Science and Molecular Medicine, 51 : 313-322. 1976.

35) Wrong $O$. Nitrogen metabolism in the gut. The Americam Journal of Clinical Nutrition, $31: 1587-$ 1593. 1978.

36) Yeo J, Kim K. Effect of feeding diets containing an antibiotic, a probiotic, or yucca extract on growth and intestinal urease activity in broiler chicks. Poultry Science, 76 : 381-385. 1997. 